\title{
OCORRÊNCIA DE MICORRIZAS ARBUSCULARES E DA BACTÉRIA DIAZOTRÓFICA ACETOBACTER DIAZOTROPHICUS EM CANA-DE-AÇÚCAR ${ }^{1}$
}

\author{
VERONICA MASSENA REIS ${ }^{2}$, MAURO AUGUSTO DE PAULA ${ }^{3}$ e JOHANNA DÖBEREINER ${ }^{4}$
}

\begin{abstract}
RESUMO - Foi avaliada a ocorrência e a distribuição de espécies de fungos micorrízicos arbusculares (FMAs) e Acetobacter diazotrophicus em plantios de cana-de-açúcar em diferentes tipos de manejo nos Estados do Rio de Janeiro e Pernambuco. Foram feitas 35 coletas de amostras de solo da rizosfera e de raízes de 14 variedades de cana-de-açúcar para extração de esporos e isolamento da bactéria. O número de esporos variou de 18 a 2.070/100 $\mathrm{mL}$ de solo, e os maiores número e diversidade de espécies foram verificados nos canaviais de Campos, RJ, especialmente naqueles que não adotam a queima do palhiço. As espécies predominantes nas três localidades amostradas foram: Acaulospora sp., Scutellospora heterogama, Glomus etunicatum, Glomus occultum e Gigaspora margarita. A. diazotrophicus estava presente nas amostras de raízes colhidas em canaviais de Campos, com exceção de uma coleta de cana-de-açúcar plantada num solo usado como bacia de sedimentação de vinhaça. Não foi possível isolar essa bactéria a partir de esporos desinfestados dos FMAs nativos, apenas dos esporos lavados com água estéril.
\end{abstract}

Termos para indexação: fungos micorrízicos arbusculares, bactéria diazotrófica endofítica, fixação biológica de nitrogênio.

\section{OCCURRENCE OF ARBUSCULAR MYCORRHIZAE AND BACTERIUM ACETOBACTER DIAZOTROPHICUS IN SUGAR CANE}

\begin{abstract}
The occurrence and distribution of species of arbuscular mycorrhizae fungi and Acetobacter diazotrophicus in sugar cane (Saccharum officinarum) grown in different regimes of crop management in the States of Rio de Janeiro and Pernambuco, Brazil, were studied. Thirty five samples of the rhizosphere soil and roots were collected from 14 varieties of sugar cane for the extraction of spores and isolation of the bacterium. The number of spores varied from 18 to 2,070 per $100 \mathrm{~mL}$ of soil, and the greatest diversity of fungal species was found in the sugarcane fields of Campos (Rio de Janeiro State), especially in those where the sugarcane trash was not burned at harvest. The predominant species found in the three localities sampled were: Scutellospora heterogama, Glomus etunicatum, Glomus occultum, Acaulospora sp. and Gigaspora margarita. A. diazotrophicus was present in almost all samples of root with the exception of one harvest of sugar cane taken from an area used for the sedimentation of vinasse (distillery waste). It was not possible to detect the bacterium from surface sterilized spores of native arbuscular mycorrhizal fungi (AMF), only from washed ones using sterile water.
\end{abstract}

Index terms: sugar cane, arbuscular mycorrhizae fungi, endophytic diazotrophic bacteria, biological nitrogen fixation.

\footnotetext{
${ }^{1}$ Aceito para publicação em 13 de janeiro de 1999. Extraído da Dissertação de Doutorado apresentada pela primeira autora à UFRRJ.

${ }^{2}$ Enga Agra , Dra , Embrapa-Centro Nacional de Pesquisa de Agrobiologia (CNPAB), Antiga Rodovia Rio/São Paulo, Km 47, Caixa Postal 74505, CEP 23890-000 Seropédica, RJ. E-mail: veronica@enpab.embrapa.br

${ }^{3}$ Eng. Agr., Ph.D., Avenida Valadares 226, CEP 37132-000 Monte Belo, MG.

${ }^{4}$ Eng ${ }^{2}$ Agr ${ }^{2}$, Ph.D., Embrapa-CNPAB.
}

\section{INTRODUÇÃO}

A cana-de-açúcar é a quinta cultura mais plantada no Brasil, não só para produção de açúcar como também de álcool combustível. É de se esperar que, com a atual crise econômica, a pesquisa venha contribuir para a utilização mais racional dos adubos químicos e a busca de técnicas que aumentem a sua absorção e seu melhor aproveitamento. Quando se avalia o benefício das bactérias 
diazotróficas para a fixação biológica de nitrogênio (FBN), a cana-de-açúcar se destaca (Boddey, 1995). Dentre as várias bactérias diazotróficas citadas, Acetobacter diazotrophicus (Gillis et al., 1989) tem sido considerada uma das mais importantes pelo seu caráter endofítico obrigatório (Baldani et al., 1997), isto é, coloniza a planta de cana-de-açúcar desde as raízes até as folhas verdes ou secas (Reis et al., 1994), os vasos do xilema (James \& Olivares, 1998) ou mesmo o apoplasto (Dong et al., 1994), mas não sobrevive no solo.

A presença de bactérias isoladas de esporos de fungos micorrízicos tem sido reportada ao longo dos anos (Varma et al., 1981; Li \& Castellano, 1987; Li \& Huang, 1987; Tilak et al.,1989). Recentemente, Bianciotto et al. (1996) descreveram a localização de uma bactéria pertencente ao gênero Burkholderia dentro do citoplasma da micorriza arbuscular Gigaspora margarita. Paula et al. (1991) estudaram a associação dessa bactéria com o fungo micorrízico arbuscular Glomus clarum inoculados em plantas micropropagadas de cana-de-açúcar e batata-doce, em condições de casa de vegetação, e observaram que o tratamento contendo o esporo do fungo, previamente cultivado na presença da bactéria A. diazotrophicus, favoreceu a colonização da parte aérea das plantas em comparação ao tratamento com a bactéria inoculada sem a presença do fungo ou mesmo no tratamento onde a bactéria e o fungo foram inoculados por ocasião do plantio. A partir de tais resultados, Paula et al. (1993) fizeram um levantamento da ocorrência da bactéria associada aos esporos de fungos micorrízicos na cultura da batata-doce, colhidos a partir de plantios comerciais, e verificaram que além dessa espécie, Klebisiela sp. e A. lipoferum também estavam presentes nos esporos lavados ou mesmo desinfestados superficialmente.

Paradoxalmente, poucos estudos sobre micorrização em cana-de-açúcar têm sido realizados, principalmente em virtude da sua baixa dependência micotrófica (Siqueira \& Franco, 1988). Sendo uma gramínea de ciclo longo, os efeitos da inoculação com fungos micorrízicos arbusculares (FMAs) não podem ser avaliados em experimentos de curta duração em casa de vegetação, onde os fatores climáticos são controlados. Deve-se salientar o fato de que nenhum estudo conclusivo foi realizado sobre a influência dos FMAs em cana-de-açúcar durante o seu ciclo vegetativo.

A diversidade das espécies e a ocorrência generalizada dos FMAs têm sido relatadas em diversas culturas. Siqueira et al. (1989) estudaram vários agrossistemas em Minas Gerais e observaram que o solo sob cultivo de cana-de-açúcar foi o que apresentou maior diversidade de espécies. Andreola (1982) realizou um levantamento de FMAs em canaviais plantados em Araras, SP, identificando sete espécies diferentes de FMAs: G. fasciculatus, G. leptothicus, A. scrobiculata, G. gilmorei, A. lavicus, G. microcarpus e Gigaspora spp. O autor concluiu que a proporção de esporos dos gêneros Acaulospora e Gigaspora foi de $4 \%$ a $30 \%$, e do gênero Glomus variou de $70 \%$ a $96 \%$. Também observou a interação desses com a temperatura, umidade e adubação mineral ou orgânica mediante o uso de vinhaça. A temperatura correlacionou de forma direta com a esporulação dos FMAs, enquanto a umidade foi inversa. O nível de fertilidade do solo não influenciou o número de esporos nem a porcentagem de colonização das raízes. Resultados semelhantes foram encontrados anteriormente por Dainese \& Cardoso (1981), em que também houve predomínio do gênero Glomus em mais de $70 \%$ das amostras.

De uma forma geral, tanto a colonização como a esporulação são influenciadas pelos fatores ambientais, pelas plantas hospedeiras e pelas espécies fúngicas envolvidas (Siqueira \& Franco, 1988). Os resultados relatados na literatura mostram uma soma de fatores atuando separadamente ou em interação (Lopes et al., 1983; Mosse, 1986). Siqueira et al. (1989) observaram que o número de espécies de FMAs foi maior nos ecossistemas naturais, porém a densidade de esporos e a taxa de colonização foram duas vezes superiores nos agrossistemas estudados.

Este trabalho objetivou avaliar a ocorrência dos FMAs e da bactéria diazotrófica endofítica A. diazotrophicus, em plantios comerciais de cana-de-açúcar e a sua presença em esporos dos FMAs. 


\section{MATERIAL E MÉTODOS}

Foram colhidas 35 amostras compostas de raízes e do solo da rizosfera de 14 variedades de cana-de-açúcar de três localidades diferentes: Estação Experimental da Embrapa-Centro Nacional de Pesquisa de Agrobiologia (CNPAB), Seropédica, RJ; em fazendas da região de Campos dos Goytacazes, RJ e na Usina Cruangi, Timbaúba, PE. As análises químicas (Embrapa, 1979) dos solos usados nas diferentes coletas estão apresentados na Tabela 1. As amostras foram separadas em solo da rizosfera para as avaliações dos FMAs e raízes lavadas para a contagem da bactéria A. diazotrophicus. As amostras também foram diferenciadas quanto ao tipo de manejo da cultura em relação à prática de queima da cana-de-açúcar por ocasião da colheita.

A extração dos esporos foi feita utilizando o método de peneiramento por via úmida (Gerdemann \& Nicolson, 1963) e separados dos fragmentos de raízes e das partículas de solo por centrifugação em água a $3.000 \mathrm{rpm}$ por três minutos em sacarose $(45 \%)$ a $2.000 \mathrm{rpm}$ por dois minutos. Após a extração, os esporos foram identificados segundo Schenck \& Perez (1988), mediante a preparação de lâminas e observações microscópicas. O número de esporos foi avaliado em $100 \mathrm{~mL}$ de solo rizosférico usando uma placa canelada.

$\mathrm{Na}$ desinfestação superficial dos esporos para a avaliação da presença da bactéria endofítica $A$. diazotrophicus associada aos esporos, foram testados seis métodos. As amostras de esporos utilizadas nos sucessivos testes foram colhidas do solo rizosférico das variedades de cana-de-açúcar da região de Campos. A avaliação da presença de $A$. diazotrophicus foi efetuada tomando-se três repetições de 50 esporos estourados sobre uma placa canelada de porcelana e inoculados em meio de cultivo semi-seletivo denominado de LGI-P (semi-sólido) sem a adição de fonte de $\mathrm{N}$ e suplementado com $0,5 \%$ de caldo de cana segundo a metodologia descrita por Reis et al. (1994). Como controle, foram utilizados três lotes de 50 esporos, peneirados, e apenas lavados com água estéril. Os métodos aplicados foram: 1. imersão por 20 minutos em hipoclorito de sódio a $0,5 \%$ seguida de três lavagens com água destilada estéril e imersão em solução de sulfato de estreptomicina $100 \mathrm{mg} \mathrm{L}^{-1}$ por 30 minutos e novamente três lavagens com água estéril (Colozzi-Filho, 1988); 2. imersão por 10 minutos em hipoclorito de sódio a $0,5 \%$ seguida de duas lavagens com água estéril e imersão em solução de sulfato de estreptomicina $100 \mathrm{mg} \mathrm{L}^{-1}$ por 10 minutos e novamente três lavagens com água estéril (Colozzi-Filho, 1988, modificado pelo autor); 3. lavagem com hipoclorito de sódio a $0,5 \%$, seguida de duas lavagens com água estéril e imersão em solução de sulfato de estreptomicina $100 \mathrm{mg} \mathrm{L}^{-1}$ por 10 minutos e seguida de três lavagens com água estéril (Colozzi-Filho, 1988, modificado pelo autor); 4 . lavagem em álcool $70 \%$, duas lavagens com água estéril e imersão em solução de cloramina-T a

TABELA 1. Análise química das amostras de solo colhidas em diversos plantios de cana-de-açúcar.

\begin{tabular}{lccccccccc}
\hline Local de amostragem & $\begin{array}{c}\mathrm{pH} \text { em } \\
\text { água }\end{array}$ & $\mathrm{Al}$ & $\mathrm{Ca}+\mathrm{Mg}$ & $\begin{array}{c}\mathrm{Ca} \\
------------\left(\mathrm{cmol}_{\mathrm{c}} \mathrm{kg}^{-1}\right)\end{array}$ & $\mathrm{Mg}$ & $\mathrm{P}$ & $\begin{array}{c}\mathrm{K} \\
\mathrm{C}\end{array}$ & $\begin{array}{c}\mathrm{N} \\
\text { Embrapa-CNPAB, RJ }\end{array}$ \\
\hline Usina Cruangi, PE & 4,4 & 0,5 & 2,0 & 1,0 & 1,0 & 0,5 & 21,0 & 6,0 & 0,8 \\
Campos, RJ $^{2}$ & 4,7 & 0,8 & 4,0 & 2,9 & 1,1 & 11,6 & 97,0 & 10,4 & 0,9 \\
1. PVA sem queima & 5,1 & 0,2 & 8,6 & 4,9 & 3,7 & 54,0 & 651,0 & 2,5 & 2,0 \\
2. PVA com queima & 5,3 & 0,1 & 9,4 & 5,6 & 3,8 & 9,8 & 150,0 & 2,1 & 1,0 \\
3. PVA sem queima & 5,0 & 0,3 & 3,8 & 2,0 & 1,6 & 8,5 & 90,0 & 1,9 & 1,0 \\
4. PVA com queima & 4,9 & 0,3 & 3,9 & 2,0 & 1,7 & 3,5 & 82,0 & 1,9 & 1,0 \\
5. Solo turfoso & 4,4 & 3,3 & 4,2 & 2,3 & 1,8 & 21,9 & 85,0 & 18,7 & 9,0 \\
6. PVA sem queima & 6,5 & 0,0 & 5,3 & 3,3 & 1,9 & 51,0 & 70,0 & 1,8 & 0,9 \\
7. PVA com queima & 6,1 & 0,0 & 3,8 & 2,2 & 1,6 & 17,0 & 168,0 & 1,5 & 0,8 \\
8. Bacia de sedimentação & 6,2 & 0,0 & 11,8 & 7,3 & 4,5 & 44,0 & 892,0 & 2,9 & 2,0 \\
\hline
\end{tabular}

1 As amostras colhidas no Campo Experimental da Embrapa-CNPAB, Seropédica, e na Usina Cruangi, Timbaúba, PE, não foram manejadas com a queima por ocasião do corte da cana-de-açúcar.

2 Local de coleta das amostras: 1, 2, 3, 4, 6, e 7: solo PVA. 8: solo usado anteriormente como bacia de sedimentação de vinhaça; 5: solo de turfa; amostras 2, 4 e 7 foram colhidas de canaviais manejados com queima por ocasião do corte da cana-de-açúcar; as outras amostras foram colhidas de canaviais que não foram queimados; a amostra 1 foi colhida de um canavial que não foi renovado por 41 anos e nunca foi queimado ou adubado. 
$1 \%$ por 10 minutos seguida de três lavagens com água estéril (Tilak et al., 1989, modificado pelo autor); 5 . imersão em solução $1: 1: 1$ de cloramina-T $2 \%$, sulfato de estreptomicina $200 \mathrm{mg} \mathrm{L}^{-1}$ e solução de dodecil-sulfato de sódio (SDS) $200 \mathrm{mg} \mathrm{L}^{-1}$ por 30 minutos seguida de três lavagens com água estéril durante 30 minutos (Nair et al., 1991, modificado pelo autor); 6. imersão em solução de cloramina-T a $2 \%$ por cinco minutos seguida de três lavagens em água estéril pelo mesmo tempo.

A avaliação da infecção de $A$. diazotrophicus foi efetuada nas raízes lavadas das amostras colhidas em Campos. As raízes foram trituradas e diluídas em solução com $100 \mathrm{~g} \mathrm{~L}^{-1}$ de sacarose. Alíquotas de $0,1 \mathrm{~mL}$ foram inoculadas em frascos contendo $5 \mathrm{~mL}$ de meio LGI-P semi-sólido contendo $0,5 \%$ de caldo de cana (Reis et al., 1994). O número de células de A. diazotrophicus foi determinado utilizando o método do número mais provável (NMP) usando-se a tabela de McCrady com três repetições por diluição (Döbereiner et al., 1995).

A comparação da eficiência da desinfestação superficial sobre a manutenção da microbiota endospórica entre os métodos 5 e 6 foi feita usando-se esporos de Glomus clarum coletado a partir de um vaso de cultivo previamente utilizado por Paula et al. (1993) com isolamento positivo para Azospirillum sp. Essa bactéria foi quantificada segundo a metodologia descrita por Döbereiner et al. (1995) usando meio de cultivo NFB.

\section{RESULTADOS E DISCUSSÃO}

Nas três localidades amostradas o número de esporos dos FMAs em solo rizosférico variou de 18 a 2.070 por $100 \mathrm{~mL}$ de solo. Na Tabela 2 são apresentados os resultados da diversidade dos FMA nas 14 variedades de cana-de-açúcar e o número médio de esporos de cada variedade nas três localidades. A maior variação no número de esporos por $100 \mathrm{~mL}$ foi observada nas amostras de Campos, (100 a 1.630), seguido da Usina Cruangi, Timbaúba, (38 a 456), e finalmente da Estação Experimental da Embrapa-CNPAB, Seropédica, (123 a 363) ordem esta também observada em relação à diversidade das espécies (Tabela 2).

Na Tabela 3, os fungos micorrízicos foram agrupados de acordo com a família e dentro desta, divididos em espécies. As amostras foram avaliadas quanto ao número de variedades que apresentaram cada espécie identificada, numa tentativa de verificar a diversidade dos fungos nas três localidades. Os canaviais amostrados em Campos apresentaram o maior número de espécies micorrízicas diferentes (14), seguidos por Timbaúba (11), e finalmente Seropédica (9), de um total de 18 espécies identificadas de FMAs. As espécies de FMAs que predominaram nas localidades estudadas foram: Acaulospora sp., S. heterogama, G. etunicatum, G. occultum, e G. margarita. Nas três localidades estudadas houve o predomínio do gênero Glomus, como observado anteriormente por Dainese \& Cardoso (1981) e Andreola (1982).

As amostras colhidas em Campos, e que foram queimadas por ocasião da colheita, apresentaram uma menor diversidade das espécies de FMAs (Tabela 4). Estudos comparativos entre a colheita de cana-de-açúcar queimada e crua demonstraram que fatores como $\mathrm{Ne} \mathrm{C}$ do solo são preservados com a manutenção do palhiço, principalmente nos primeiros $20 \mathrm{~cm}$ de profundidade (Oliveira et al., 1994). A matéria orgânica mantida no canavial

TABELA 2. Número médio de esporos e número de espécies de fungos micorrízicos arbusculares (FMAs) presentes na rizosfera de 14 variedades de cana-de-açúcar colhidas em três localidades.

\begin{tabular}{lccc}
\hline \multirow{2}{*}{ Variedades } & \multicolumn{3}{c}{ Local } \\
\cline { 2 - 2 } Sernambuco & \multicolumn{2}{c}{ Rio de Janeiro } \\
\cline { 2 - 3 } SP71-1143 & Timbaúba & Seropédica & Campos \\
SP71-1407 & $38 / 4^{2}$ & $363 / 7$ & $255 / 6$ \\
SP72-1454 & $114 / 5$ & & \\
CB 45-3 & $456 / 4$ & & \\
CO 997 & $165 / 8$ & & $352 / 4$ \\
NA 56-79 & $165 / 8$ & & \\
CB 47-89 & $71 / 3$ & $123 / 3$ & \\
KRACATAU & & $336 / 3$ & \\
Saccharum sp. & & $219 / 4$ & \\
CB 49-27 & & $344 / 6$ & $196 / 8$ \\
CB 14-06 & & & $1030 / 7$ \\
SP70-1284 & & & $100 / 5$ \\
RB 72-454 & & & 593 \\
\hline Média de & 158 & 277 & \\
esporos por local & & & \\
\hline
\end{tabular}

1 Número médio de esporos.

2 Número de espécies. 
pode ser um fator positivo na manutenção das estruturas de propagação dos FMAs (hifas ou esporos) como observado anteriormente por Kruckelmann (1975). Outro fator importante é a preservação da umidade do solo, fundamental principalmente na região de Campos, onde a cultura da cana-de-açúcar sofre constantemente problemas de queda de produtividade por falta de chuvas. Embora os resultados apresentados não sejam conclusivos, a manutenção da palhada pode beneficiar os FMAs e outros componentes da microbiota do solo ao longo do tempo.

Quando se compara o número de esporos (Tabela 5) com a composição química das amostras de solo (Tabela 1), observa-se no solo de turfa (amostra 5 - Campos) maior número de esporos (2.032 esporos por $100 \mathrm{~mL}$ de solo), o que pode estar relacionado com seu elevado teor de C $(18,7 \%)$. Além disso, os esporos colhidos diretamente do campo apresentavam-se menos infestados por parasitas, resultando numa observação mais clara quanto a integridade das paredes, coloração e conteúdo celular dos esporos de FMAs. A amostra 1, coletada em canavial implantado há 41 anos, sem renovação e sempre manejado sem queima por ocasião da colheita,também apresentou um número elevado de esporos (1.630 esporos por $100 \mathrm{~mL}$ ).

A presença de $A$. diazotrophicus avaliada nas raízes lavadas das variedades colhidas em Campos (Tabela 5) permitiu verificar a associação dessa bactéria com a sua planta hospedeira. $A$. diazotrophicus estava presente em quase todas as amostras de raízes, excetuando-se naquela colhida de um solo usado como bacia de sedimentação de vinhaça (amostra 8). Entretanto, a amostra 1 do canavial sem renovação por quatro décadas, apre-

TABELA 3. Diversidade de espécies de FMAs associados a diferentes variedades de cana-de-açúcar plantadas em três localidades.

\begin{tabular}{|c|c|c|c|c|}
\hline \multirow[t]{3}{*}{ Espécies de FMAs } & \multicolumn{4}{|c|}{ Número de variedades que apresentaram a espécie } \\
\hline & \multirow{2}{*}{$\begin{array}{c}\text { Pernambuco } \\
\text { Timbaúba } \\
\end{array}$} & \multicolumn{2}{|c|}{ Rio de Janeiro } & \multirow[t]{2}{*}{ Tota } \\
\hline & & Seropédica & Campos & \\
\hline \multicolumn{5}{|c|}{ Família Gigasporaceae } \\
\hline G. margarita & 4 & 3 & 1 & 8 \\
\hline G. gigantea & 0 & 0 & 1 & 1 \\
\hline G. gregaria & 4 & 0 & 0 & 4 \\
\hline Gigaspora sp. & 1 & 0 & 2 & 3 \\
\hline \multicolumn{5}{|l|}{ Família Glomaceae } \\
\hline G. etunicatum & 4 & 4 & 4 & 12 \\
\hline G. diaphanum & 0 & 0 & 2 & 2 \\
\hline G. macrocarpum & 0 & 3 & 3 & 6 \\
\hline G. clanim & 0 & 1 & 0 & 1 \\
\hline G. occultum & 2 & 1 & 6 & 9 \\
\hline Glomus sp. & 4 & 1 & 1 & 6 \\
\hline \multicolumn{5}{|c|}{ Família Acaulosporaceae } \\
\hline A. scrobiculata & 1 & 0 & 0 & 1 \\
\hline Entrophospona sp. & 1 & 0 & 0 & 1 \\
\hline Acaulospora sp. 1 & 5 & 3 & 6 & 14 \\
\hline Acaulospora sp. 2 & 0 & 0 & 4 & 4 \\
\hline Acaulospora sp. 3 & 0 & 0 & 1 & 1 \\
\hline Acaulospora sp. & 0 & 0 & 1 & 1 \\
\hline S. heterogama & 6 & 5 & 2 & 13 \\
\hline Scutellospora sp. & 3 & 1 & 1 & 5 \\
\hline
\end{tabular}


sentou um elevado número de $A$. diazotrophicus por $\mathrm{g}$ de raízes frescas. Reis et al. (1994) avaliando a colonização de $A$. diazotrophicus nessa localidade observou que a bactéria estava presente nas raízes, colmos, folhas verdes, secas e também no palhiço (folhas caídas), com números em torno de $10^{6}$ células por $\mathrm{g}$ de peso fresco.

Uma vez que $A$. diazotrophicus estava presente na maioria das amostras avaliadas (exceção da amostra 8 - Campos) foi dada continuidade à avaliação de sua presença nas amostras de esporos separados por peneiramento úmido, lavados e separados em lotes de 50 esporos cada. Os métodos de desinfestação superficial utilizados foram selecionados a partir da literatura disponível, acrescido de algumas modificações feitas pelos autores, com o

TABELA 4. Efeito da queima da cana-de-açúcar por ocasião do corte na diversidade das espécies de FMAs colhidos em canaviais da região de Campos, RJ.

\begin{tabular}{ccc}
\hline Espécie de FMAs & \multicolumn{2}{c}{$\begin{array}{c}\text { Número de variedades que } \\
\text { apresentaram a espécie }\end{array}$} \\
\cline { 2 - 3 } & Sem queima & Com queima \\
\hline
\end{tabular}

Família Gigasporaceae

\begin{tabular}{lll} 
G. margarita & 1 & 0 \\
G. gigantea & 1 & 0 \\
G. gregaria & 0 & 0 \\
Gigaspora sp. & 4 & 1 \\
\hline
\end{tabular}

Família Glomaceae

\begin{tabular}{lll} 
G. etunicatum & 4 & 2 \\
G. diaphanum & 1 & 1 \\
G. macrocarpum & 2 & 1 \\
G. clarum & 0 & 0 \\
G. occultum & 6 & 4 \\
Glomus sp. & 5 & 3 \\
\hline
\end{tabular}

\begin{tabular}{lcc}
\hline Família Acaulosporaceae & & 3 \\
A. scrobiculata & 0 & 0 \\
Entrophospora sp. & 0 & 0 \\
Acaulospora sp. 1 & 6 & 4 \\
Acaulospora sp. 2 & 0 & 0 \\
Acaulospora sp. 3 & 0 & 0 \\
Acaulospora sp. 4 & 0 & 0 \\
S. heterogama & 2 & 1 \\
Scutellospona sp. & 1 & 0 \\
\hline Total de variedades & 33 & 17 \\
\hline
\end{tabular}

objetivo de manter um equilíbrio entre desinfestar o esporo sem perder a viabilidade das células de bactérias que poderiam estar ali associadas (bactérias endospóricas). Mesmo com as modificações efetuadas nos métodos originais, só foi possível detectar a presença da bactéria $A$. diazotrophicus, a partir de esporos de FMAs nativos, nos esporos lavados com água estéril. Como esporos são estruturas de resistência, a atividade metabólica é reduzida ao mínimo, e sendo esporos peneirados diretamente do solo sob cultivo, poderiam estar colonizados por outros fungos saprófitas ou mesmo outras bactérias nativas, e pode ter ocorrido uma competição por fonte de $\mathrm{C}$ e $\mathrm{N}$ nas condições avaliadas, impedindo o crescimento de A. diazotrophicus no meio de cultivo LGI-P. Também podemos levantar a hipótese de que, sob condições de campo, o número de esporos de FMAs nativos que poderiam estar associados à bactéria endófita $A$. diazotrophicus seja pequeno e que a metodologia utilizada para a contagem não foi capaz de detectá-los. Entretanto, bactérias podem adotar uma forma de economia energética descrita na literatura como viável mas não cultivável, e desta forma não seriam capazes de crescer mesmo em meio de cultivo completo, contendo N, vitaminas e outras substâncias tais como aminoácidos (meio rico). Paula et al. (1993) isolou A. diazotrophicus, A. lipoferum e Klebisiela spp. de esporos colhidos na rizosfera de batata-doce, tanto de esporos lavados com água estéril como

TABELA 5. Ocorrência da bactéria endofítica A. diazotrophicus e de esporos de FMAs em solo cultivado com cana-de-açúcar em Campos, RJ. (Médias de duas repetições).

\begin{tabular}{lcc}
\hline Variedade & $\begin{array}{c}\text { Raiz lavada } \\
\left(\mathrm{n}^{\mathrm{o}} \text { de células por }\right. \\
\mathrm{g} \mathrm{de} \text { matéria fresca) }\end{array}$ & $\begin{array}{c}\text { Solo rizosférico } \\
\left(\mathrm{n}^{\mathrm{o}} \text { de esporos }\right. \\
\text { por } 100 \mathrm{~mL})\end{array}$ \\
\hline CB 36-14 & $1,4 \times 10^{6}$ & 1.630 \\
CB 45-3 & $2,3 \times 10^{5}$ & 352 \\
SP70-1284 & $1,7 \times 10^{5}$ & 808 \\
CB 49-27 & $2,5 \times 10^{4}$ & 240 \\
SP70-1284 & $1,4 \times 10^{5}$ & 2.032 \\
RB 72-454 & $5,6 \times 10^{6}$ & 100 \\
SP70-1143 & $7,5 \times 10^{4}$ & 255 \\
SP70-1284 & 0,0 & 245 \\
\hline
\end{tabular}


desinfestados superficialmente e estourados. Porém, apenas um único isolamento positivo das três espécies foi feito a partir de esporos nativos esterilizados, e no caso de $A$. diazotrophicus só houve crescimento positivo nos vasos de cultivo inoculados com a bactéria. Por outro lado, outra espécie de bactéria diazotrófica, $A$. lipoferum, de ocorrência mais generalizada e considerada como um endófito facultativo, foi isolada de esporos lavados ou desinfestados. Já a espécie Klebisiela spp., que possui uma ocorrência mais generalizada, foi observada em todas as amostras de rizosfera de batata. Esses autores sugeriram que os métodos de desinfestação superficial não são capazes de eliminar $100 \%$ dos microorganismos associados aos esporos, e que esta microbiota poderia estar localizada nas incrustações das paredes e hifas de sustentação ou mesmo no lúmem dos esporos, como observado por Bianciotto et al. (1996). Também devemos ressaltar que no trabalho de Paula et al. (1993), foi aplicado o método tradicional de isolamento a partir de meio de cultivo e que outros métodos cujo número mínimo de detecção seja inferior a 100 células por $\mathrm{mL}$ (nível mínimo do método de MacCrady) podem ajudar a esclarecer a colonização dos esporos por bactérias, como no trabalho de Bianciotto et al. (1996).

Quanto ao tipo de tratamento aplicado na desinfestação dos esporos, foi observado que o tratamento utilizando álcool 70\% (método 4) acarretou uma rápida oxidação dos esporos enquanto os métodos utilizando hipoclorito de sódio tenderam a descolori-los. Os métodos 1, 2, 3 e 4 utilizados neste trabalho, foram empregados em ensaios que exigiam uma desinfestação completa dos esporos, pois estes foram usados posteriormente em ensaios gnotobióticos.

O método de desinfestação superficial, utilizado por Nair et al. (1991) (método 6), foi usado num estudo comparativo com o método 5 para se verificar a eficiência e manutenção da microbiota associada aos esporos. Num lote de 600 esporos do fungo Glomus clarum que estava colonizado com a bactéria Azospirillum sp., ocorreu uma redução da ordem de 100 vezes da população de A. lipoferum isolados a partir dos esporos lavados com água estéril cuja população foi de $2,1 \times 10^{4}$ para os desinfestados superficialmente aplicando-se o método 6, que resultou numa população de $9,5 \times 10^{2}$. Usando o método 5 , não foi possível detectar nenhuma célula da bactéria em seu meio de cultivo seletivo (NFB). Desta forma, recomenda-se que, para estudos sobre a associação de bactérias a esporos de FMAs colhidos diretamente do campo, o uso de cloramina-T a $2 \%$ por cinco minutos (método 6). O uso do tratamento de desinfestação para obtenção de esporos livres de fungos e bactérias em geral, também elimina completamente a microflora endospórica. Entretanto, o uso de cloramina-T pareceu eliminar somente a população que habitava a superfície do esporo. O uso da cloramina- $\mathrm{T}$ tem como vantagem o tamanho da molécula que é de difícil penetração em membranas e tem sido amplamente utilizada em esterilizações superficiais de raízes de plantas.

\section{CONCLUSÕES}

1. Fungos micorrízicos vesículo-arbusculares (FMAs) ocorrem naturalmente na rizosfera de plantas de cana-de-açúcar sob diferentes condições de solos e manejo.

2. O número de esporos dos FMAs nas plantas de cana-de-açúcar apresenta variações quantitativas e qualitativas entre as localidades amostradas.

3. A prática da queima da cana-de-açúcar por ocasião do corte diminui a diversidade das espécies de FMAs nativos.

4. A bactéria diazotrófica endofítica Acetobacter diazotrophicus está presente em amostras de cana-de-açúcar colhidas a partir de raízes e nos esporos de FMAs nativos lavados com água estéril.

5. Acetobacter diazotrophicus não está associada a esporos de FMAs nativos submetidos a diversos métodos de desinfestação superficial.

\section{REFERÊNCIAS}

ANDREOLA, F. Micorriza MVA em cana-de-açúcar. Piracicaba: USP-ESALQ, 1982. 74p. Tese de Mestrado.

BALDANI, I.; CARUSO, L.; BALDANI, V.L.D.; GOI, S.R.; DÖBEREINER, J. Recent advances in BNF with non-legume plants. Soil Biology and Biochemistry, Oxford, v.29, p.911-922, 1997.

Pesq. agropec. bras., Brasília, v.34, n.10, p.1933-1941, out. 1999 
BIANCIOTTO, V.; BANDI, C.; MINERDI, D.; SIRONI, M.; TICHY, H.V.; BONFANTE, P. An obligately endosymbiotic mycorrhizal fungus itself harbora obligately intracellular bacteria. Applied and Environmental Microbiology, Washington, v.62, p.3005-3010, 1996

BODDEY, R.M. Biological nitrogen fixation in sugar cane: A key to energetically viable biofuel production. Critical Reviews in Plant Sciences, Boca Raton, v.14, p.263-279, 1995.

COLOZZI-FILHO, A. Desinfestação superficial de esporos de fungos micorrízicos vesículoarbusculares. Lavras: ESAL, 1988. 80p. Tese de Mestrado.

DAINESE, M.B.; CARDOSO, E.J.B.N. Algumas observações sobre fungos micorrízicos em associação com a cana-de-açúcar em Piracicaba. O Solo, Piracicaba., v.73, p.24-27, 1981

DÖBEREINER, J.; BALDANI, I.; BALDANI, V.L.D. Como isolar e identificar bactérias diazotróficas de plantas não-leguminosas. Brasília: Embrapa-SPI 1995. 60p

DONG, Z.; CANNY, M.J.; MCCULLY, M.E.; ROBOREDO, M.R.; CABADILLA, C.F.; ORTEGA, E.; RODÉS, R. A nitrogen-fixing endophyte of sugarcane stems. A new role for the apoplast. Plant Physiology, Rockville, v.105, p.1139-1147, 1994

EMBRAPA. Serviço Nacional de Levantamento e Conservação de Solos (Rio de Janeiro, RJ). Manual de métodos de análise de solo. Rio de janeiro, 1979. n.p

GERDEMANN, J.W.; NICOLSON, T.H. Spores of mycorrhizal endogone species extracted from soil by wet sieving and decanting. Transactions of the British Mycological Society, Cambridge, v.6, p.235-246, 1963.

GILLIS, M.; KERSTERS, K.; HOSTE, B.; JANSSENS, D.; KROPPEENSTEDT, R.M.; STEPHAN, M.P.; TEIXEIRA, K.R. do S.; DÖBEREINER, J.; DE LEY, J. Acetobacter diazotrophicus sp. nov., a nitrogen-fixing acetic acid bacterium associated with sugar cane. International Journal of Systematic Bacteriology, Washington, v.39, p.361-364, 1989

JAMES, E.K.; OLIVARES, F.L. Infection and colonization of sugar cane and other graminaceous plants by endophytic diazotrophs. Critical Reviews in Plant Sciences, Boca Raton, v.17, p.77-119, 1998.

KRUCKELMANN, H.W. Effects of fertilizers, soil tillage, and plant species on the frequency of Endogone clamydospore and mycorrhizal infection on arable soil. In: SANDERS, F.E.; MOSSE, B.; TINKER, P.B. (Eds.). Endomycorrhizas. London: Academic, 1975. p.511-525.

LI, C.Y.; CASTELLANO, M.A. Azospirillum isolated from within sporocarpus of mycorrhizal fungi Hebeloma cristuliniforme, Laccaria laccata and Rhizopogon vinicolor. Transactions of British Mycological Society, Cambridge, v.88, p.563-565, 1987.

LI, C.Y.; HUANG, L.L. Nitrogen-fixing (acetylenereducing) bacteria associated with endomycorrhizal of Douglas-fir. Plant and Soil, Dordrecht, v.98, p.425-429, 1987.

LOPES, E.S.; SIQUEIRA, J.O.; ZAMBOLIN, L. Caracterização das micorrizas vesiculo-arbusculares (MVA) e seus efeitos no crescimento das plantas. Revista Brasileira de Ciência do Solo, Campinas, v.7, p.1-19, 1983.

MOSSE, B. Mycorrhiza in a sustainable agriculture Biological Agriculture \& Hortcultural, Oxon, v.3, p.191-209, 1986.

NAIR, M.G.; SAFIR, G.R.; SIQUEIRA, J.O. Isolation and identification of vesicular-arbuscular mycorrhizastimulatory compounds from clover (Trifolium repens) roots. Applied and Environmental Microbiology, Washington, v.57, p.434-439, 1991.

OLIVEIRA, O.C.; URQUIAGA, S.; BODDEY, R.M. Burning cane: the long-term effects. International Sugar Journal, Bucks, v.96, p.272-275, 1994.

PAULA, M.A.; REIS, V.M.; DÖBEREINER, J. Interactions of Glomus clarum with Acetobacter diazotrophicus in infection of roots and tops of sweet potato (Ipomea batatas) sugar cane (Saccharum sp.) and sweet sorghum (Sorghum vulgare). Biology and Fertility of Soils, Berlin, v.11, p.111-115, 1991.

PAULA, M.A.; SIQUEIRA, J.O.; DÖBEREINER, J Ocorrência de fungos micorrízicos vesiculoarbusculares e de bactérias diazotróficas na cultura da batata-doce. Revista Brasileira de Ciência do Solo, Campinas, v.17, p.349-356, 1993. 
REIS, V.M.; OLIVARES, F.L.; DÖBEREINER, J Improved methodology for isolation and identification of Acetobacter diazotrophicus and confirmation of its endophytic habitat. World Journal of Microbiology and Biotechnology, Oxford, v.10, p.401-405, 1994.

SCHENCK, N.C.; PEREZ, Y. Manual for identification of VA mycorrhizal fungi. 24.ed. Florida: University of Florida, 1988. 241p.

SIQUEIRA, J.O.; COLOZZI-FILHO, A.; OLIVEIRA, E. de. Ocorrência de micorrizas vesicular-arbusculares em agro e ecossistemas do Estado de Minas Gerais.
Pesquisa Agropecuária Brasileira, Brasília, v.24, n.12, p.1499-1506, 1989

SIQUEIRA, J.O.; FRANCO, A.A. Biotecnologia do solo: fundamentos e perspectivas. Brasília: MEC/ABEAS/Lavras: ESAL/FAEPE, 1988. 236p.

TILAK, K.V.B.R.; LI, C.Y.; HO, I. Occurrence of nitrogenfixing Azospirillum in a vesicular-arbuscular mycorrhizal fungi. Plant and Soil, Dordrecht, v.116, p.286-288, 1989.

VARMA, A.K.; SINGH, K.; LALL, K. Lumen bacteria from endomycorrhizal spores. Current Microbiology, New York, v.6, p.207-211, 1981. 